Research, Society and Development, v. 9, n. 8, e325985250, 2020

(CC BY 4.0) | ISSN 2525-3409 | DOI: http://dx.doi.org/10.33448/rsd-v9i8.5250

Unidade temática sobre limpeza no ensino de Química: um exemplar da perspectiva de

\title{
Ciência, Tecnologia e Sociedade
}

Thematic unit on cleaning in Chemistry teaching: an example of the perspective of

Science, Tech and Society

Unidad temática sobre la limpieza en la enseñanza de la Química: un ejemplo de la perspectiva de la Ciencia, Tecnologia e Sociedad

Recebido: 03/06/2020 | Revisado: 23/06/2020 | Aceito: 24/06/2020 | Publicado: 06/07/2020

Franciela Arenhart Soares

ORCID: https://orcid.org/0000-0002-6624-9533

Universidade Federal do Rio Grande do Sul, Brasil

E-mail: fransoares05@hotmail.com

Ágatha Lottermann Selbach

ORCID: https://orcid.org/0000-0001-8348-3017

Universidade Federal do Rio Grande do Sul, Brasil

E-mail: agatha.selbach@ hotmail.com

Camila Greff Passos

ORCID: https://orcid.org/0000-0003-1110-9354

Universidade Federal do Rio Grande do Sul, Brasil

E-mail: camila.passos@ufrgs.br

\section{Resumo}

Este artigo teve como objetivo avaliar as formas de contribuição da Unidade Temática (UT) “A Química da Limpeza" para a abordagem de conteúdos de geometria molecular, polaridade, solubilidade e interações intermoleculares em quatro turmas de primeiro ano do Ensino Médio de uma escola estadual de Porto Alegre. Assim, foi elaborada uma UT, fundamentada na perspectiva Ciência, Tecnologia e Sociedade (CTS), contendo recursos didáticos variados como atividades de leitura, experimentação, produção de modelos físicos e exercícios contextualizados com a temática da limpeza. Os dados foram coletados com a aplicação de questionários aos alunos e com os registros do Diário de Campo. Os resultados apontam que o material didático é flexível e apresenta potencialidades para o ensino de Química, tanto em aspectos conceituais, como para incitar a reflexão crítica sobre análise de rótulos e consumo consciente de produtos de higiene. 
Palavras-chave: Unidade temática; Contextualização; Ensino de Química.

\begin{abstract}
The goal of this paper was to evaluate the ways of contribution of the Thematic Unit (TU) “The Chemistry of Cleaning", to approach subjects as molecular geometry, polarity, solubility and intermolecular forces in four classes of first year's students of High School in a Public School from Porto Alegre. Thus, a TU was elaborate reasoned in a STS perspective, containing several didactic resources such as reading activities, experiments, physical model's production and exercises put it into cleaning context. The data were collected with questionnaires applied with the students and with notes in the Field Diary. The result shows that the didactic material is flexible and presents a lot of potential to the Chemistry teach, in conceptual aspects and inciting the critical reflection about label analysis and conscious consumption of hygiene products.
\end{abstract}

Keywords: Thematic Unit; Contextualization; Chemistry teaching.

\title{
Resumen
}

En este artículo, buscamos evaluar las formas de contribución de la Unidad temática (UT) "La química de la limpieza" para abordar los contenidos de geometría molecular, polaridad, solubilidad e interacciones intermoleculares en cuatro clases de primer año de una escuela secundaria en una escuela estatal de Porto Alegre Por lo tanto, se elaboró una UT, basada en la perspectiva de Ciencia, Tecnología y Sociedad (CTS), que contenía recursos didácticos variados como actividades de lectura, experimentación, producción de modelos físicos y ejercicios contextualizados con el tema de la limpieza. Los datos fueron recolectados con la aplicación de cuestionarios a los estudiantes y con los registros del diario de campo. Los resultados muestran que el material de enseñanza es flexible y tiene potencial para enseñar Química, tanto en aspectos conceptuales, como para alentar la reflexión crítica sobre el análisis de etiquetas y el consumo consciente de productos de higiene.

Palabras clave: Unidad temática; Contextualización; Enseñanza de la Química.

\section{Introdução}

Em um momento em que o próprio papel do Ensino Médio é questionado com as alterações da Lei de Diretrizes e Bases da Educação Básica (Brasil, 1996), é preciso refletir acerca da importância do ensino de ciências, mais especificamente de Química, na formação 
de cidadãos preparados e capazes de interagir com a sociedade. Sabe-se que a Química, no modelo tradicional de ensino, é abordada como uma ciência descontextualizada e sem interação com o meio social, promovendo o desinteresse e altas taxas de reprovação nas escolas (Silva \& Marcondes, 2010).

Dentre as diversas estratégias para um ensino de Química contextualizado e abrangente ao estudante, podem ser citadas a utilização de mapas conceituais, atividades experimentais investigativas, abordagens temáticas, estudos de caso, entre diversas outras. Tais estratégias têm-se mostrado cada vez mais propícias para o desenvolvimento de habilidades Químicas, como a linguagem, aplicação de conceitos e fórmulas (Santos, 2007). Além disso, o emprego de metodologias diferenciadas no ensino de Química, também permitem o estímulo da curiosidade e a formação de alunos mais conscientes.

Por outro lado, essas estratégias requerem uma demanda de planejamento, superior às atividades comumente empregadas no método tradicional de ensino, o qual exige apenas uma postura passiva dos alunos e onde o professor é o detentor e transmissor do conhecimento. Assim, a utilização de diferentes estratégias de ensino, estimula a produção de material didático, o que contribui fortemente para a formação dos professores de Química (Silva \& Marcondes, 2015).

A utilização de Unidades Temáticas (UT) no ensino de Química permite justamente que, tanto as habilidades na produção do material didático por parte do professor, como as habilidades e competências em Química do aluno sejam desenvolvidas (Santos, 2007). As UT podem auxiliar um estudo mais contextualizado, do ponto de vista do grande número de exemplos que podem ser utilizados, além de promover o caráter cidadão do aluno. Isto é, o aluno se torna crítico àquilo que conhece.

Os produtos de higiene e beleza representam uma série de produtos utilizados cotidianamente por todos e dão origem a uma abordagem temática com grande potencial para ser empregada em diversos momentos no ensino de Química, devido a extensão do tema e de sua proximidade com os alunos (Faria et al., 2016). A Química dos produtos de higiene e beleza pode ser empregada no primeiro ano do ensino médio, como, por exemplo, no estudo das ligações Químicas, interações intermoleculares, no segundo ano, no estudo de reações Químicas e a estequiometria, e ainda no terceiro ano, no estudo de grupos funcionais.

Tendo em vista a importância do tema na sociedade urbana atual e também a sua fácil correlação com os conteúdos previstos para o primeiro ano do Ensino Médio, propôs-se a UT "A Química da limpeza". O objetivo central deste trabalho consiste em identificar as formas de contribuição da utilização da referida UT para o ensino de Química, referente aos 
conteúdos conceituais de geometria molecular, polaridade, solubilidade e interações intermoleculares. Também serão explorados e articulados os desafios encontrados para a sua elaboração e as dificuldades encontradas tanto pelo professor, como pelos alunos em sua utilização.

\section{Referencial Teórico}

\subsection{Contextualização no Ensino de Ciências}

No ensino de ciências da natureza, a contextualização exerce um papel central como princípio norteador para uma educação problematizadora, isto é, uma educação que permita compreender, atuar e transformar de forma consciente o meio social (Delizoicov, 2008). Para Lutfi (1992) a contextualização no ensino de Química pode ir desde a resposta às curiosidades levantadas pelos alunos, até a elaboração de projetos que visem informar sobre a ciência e suas tecnologias e que permitam ao aluno realizar transformações na realidade. Já para Santos \& Mortimer (2002), a contextualização pode ter três entendimentos: primeiro, pode ser utilizada como estratégia para a aprendizagem; segundo, pode atuar como descrição científica de fenômenos comuns à realidade do aluno; e terceiro, pode auxiliar no desenvolvimento de atitudes e valores.

Contudo, como apontado por Silva e Marcondes (2010), apesar dos discursos favoráveis à transformação do ensino de ciências, em muitas escolas ainda se encontram currículos engessados, estagnados no conteudismo, e que dificultam uma abordagem contextualizada. Nesse sentido, corre-se o risco de que a contextualização por meio de temáticas do cotidiano sirva apenas para a introdução de conteúdos teóricos ou para motivar a curiosidade do aluno (Chassot, 2001).

De modo semelhante, Halmenschlager \& Delizoicov (2017) apontam que existem duas naturezas para o uso de temáticas em sala de aula: conceitual e contextual. A natureza conceitual envolve aspectos relacionados com a conceituação científica e uso dela em situações da vivência do aluno. "Ou seja, tem relação direta com a estrutura conceitual que tradicionalmente orienta a organização dos programas escolares" (p.307). Por outro lado, a natureza contextual deriva de situações representativas de um determinado contexto geopolítico, ambiental, etc. O desafio, justamente, consiste em estabelecer relações entre o contexto e a temática, de modo que a interpretação do tema se dê por parâmetros inéditos aos alunos. 


\subsection{A Abordagem CTS}

O movimento Ciência-Tecnologia-Sociedade (CTS) surgiu na década de 1970 como uma crítica ao modelo tradicional de desenvolvimento científico e tecnológico, aos problemas políticos e econômicos relacionados ao desenvolvimento científico e aos problemas ambientais decorrentes do pós-guerra, que passam a intervir de modo crescente na vida das pessoas (Roehrig, Assis \& Czelusniaki, 2011). Desse modo, em países da Europa foram propostos currículos em que a abordagem CTS estivesse incluída, daí o caráter acadêmico da proposta, que contava com cientistas, engenheiros sociólogos e humanistas. Nos Estados Unidos, o movimento, com caráter social, surgiu como forma de questionar as consequências sociais do desenvolvimento científico-tecnológico e contava com a participação de grupos pacifistas, ativistas de direitos humanos e associações de consumidores (Strieder \& Kawamura, 2017). De modo geral, o movimento trouxe consigo o rompimento com a visão neutra e salvacionista da ciência, bem como passou a questionar o papel da tecnologia na determinação dos caminhos percorridos pela sociedade e ciência (Giffoni, Barroso \& Sampaio, 2020; Silva \& Marcondes, 2010).

Na América Latina, a abordagem de temas CTS estava incluída no Pensamento Latino-Americano em CTS - PLACTS - (Dagnino et al, 2003 - como citado em Dagnino \& Thomas, 2003, p. 51-95). O PLACTS caracterizava-se principalmente por questionar o modelo de produção de ciência e tecnologia baseado em países de primeiro mundo e empregado nos países em desenvolvimento latino-americanos. O intuito era modificar o desenvolvimento da ciência e tecnologia por meio de políticas científico-tecnológicas (Strieder \& Kawamura, 2017).

No Brasil, a década de 1990 é considerada um marco para educação envolvendo o movimento CTS, pois foi nessa década que tiveram início diversas pesquisas envolvendo a temática (Auler, 2002; Cruz, 2001; Santos, 1992). Também é preciso destacar que em 1990 se deu a primeira "Conferência Internacional Ensino de Ciências para o Século XXI: ACT Alfabetização em Ciência e Tecnologia”, cuja temática central foi à educação científica dos cidadãos (Strieder \& Kawamura, 2017).

O movimento CTS está fortemente relacionado à contextualização no ensino médio e possui elementos comuns à filosofia e teoria freireana, porém tem caráter diferenciado. Isto é, enquanto que na abordagem freireana os temas geradores surgem por apontamentos dos estudantes ou identificados como necessidades da comunidade escolar, na abordagem CTS o tema normalmente é sugerido pelo professor a partir de uma triagem sobre os interesses dos 
alunos e as necessidades de aprendizagens quanto à ciência, tecnologias e suas aplicações na sociedade (Auler, Dalmolin \& Fenalti, 2009; Giffoni, Barroso \& Sampaio, 2020). Para Strieder \& Kawamura (2017), no Brasil, a educação CTS tem como propósitos educacionais o desenvolvimento de percepções, questionamentos e compromissos sociais. Esses propósitos se assemelham à filosofia apresentada por Freire, onde o aluno é o promotor do conhecimento.

No que tange ao ensino de Química, os trabalhos de Wildson Luiz Pereira dos Santos vêm sendo referência desde a década de 1990. Para o autor, a abordagem de temas CTS tem por objetivo promover a educação científica e tecnológica dos alunos, de forma a desenvolver habilidades, construir saberes e adquirir os valores necessários para atuarem como cidadãos responsáveis em áreas relacionadas à ciência e ao emprego de suas tecnologias na sociedade (Santos, 1992). Além disso, a abordagem de temas CTS no ensino de Química permite a formação de cidadãos mais conscientes e que estes tenham participação em decisões públicas, as quais acabam muitas vezes ficando restritas a parcelas mais elitizadas da população. Em outras palavras, o ensino de Química por meio de abordagens temáticas pode auxiliar na promoção da democracia, pois possibilita a formação de um aluno consciente de seu papel na sociedade (Santos \& Mortimer, 2002).

Ibid (2002) também apontam quais os elementos curriculares que compreendem o ensino CTS. Para os autores, o objetivo da educação CTS é o desenvolvimento de valores vinculados aos interesses coletivos e, portanto, contrários à ordem capitalista, no qual os valores econômicos se impõem aos demais. Dessa forma, tem-se uma estrutura conceitual composta pelos seguintes temas: conceitos científicos e tecnológicos, processos de investigação e interações entre ciência, tecnologia e sociedade. Esses temas têm como função estimular a participação ativa dos alunos na coleta de informações, resolução de problemas e tomada de decisões. Ainda, para os autores, a interação entre ciência, tecnologia e sociedade seria o meio para o desenvolvimento de valores e ideias abordados e construídos por meio do estudo de temas locais, globais e de políticas públicas.

Do ponto de vista da formação do aluno como cidadão ativo, a proposta curricular de CTS segue uma perspectiva política da ciência, uma vez que se baseia na integração entre educação científica, tecnológica e social, onde os conteúdos científicos e tecnológicos são estudados juntamente com a discussão de seus aspectos históricos, éticos, políticos e socioeconômicos. 
Desse modo, entende-se que para o ensino de ciências a abordagem CTS converge com as atuais demandas por discussões que perpassem o contexto escolar, como a necessidade de formação de alunos mais conscientes de seu papel na sociedade.

\subsection{Produção de Material Didático}

A presença constante em documentos oficiais do emprego de temáticas como estratégia de ensino na área de ciências e, mais especificamente, no ensino de Química, denota a importância de estudos como o apresentado neste artigo. Contudo, seja por motivos diversos como o despreparo dos professores, falta de incentivo salarial, falta de tempo para planejamento e desenvolvimento de materiais didáticos adequados devido à alta carga de trabalho em uma ou mais escolas, ou até mesmo pela incompatibilidade advinda do choque entre aquilo que se espera do professor e o que é repassado em sala de aula, pouco se tem efetivamente observado nas escolas no sentido de modificação do ensino de modo tradicional. A abordagem utilizada nas escolas dá preferência aos conteúdos, os quais são apresentados de forma descontextualizada, na forma de memorização de conceitos e, principalmente, sem posicionamento crítico do aluno (Toma, Greca \& Meneses-Villagrá, 2017).

Uma forma de se desprender do método de ensino tradicional é a busca por materiais didáticos considerados alternativos, ou a elaboração dos mesmos. Na década de 1990, diversos pesquisadores como Chassot (1993), Del Pino et al. (1993) e Lufti (1992), buscaram produzir material didático inovador e criar canais de divulgação dos materiais desenvolvidos. Esses materiais tinham como objetivo romper com as deficiências e inadequações dos materiais tradicionais, por meio da contextualização de conceitos químicos.

Como pode ser observado na literatura, há um considerável número de trabalhos envolvendo o uso de temáticas, e por consequência, elaboração de material didático para o ensino de Química, abrangendo diversos temas como, água, agrotóxicos, drogas ou alimentos (Silva \& Gomes, 2015). O número expressivo de trabalhos indica, segundo Halmenschlager \& Delizoicov (2017), que estão sendo realizadas tentativas de construir opções curriculares que articulem temas e conceituação científica. Além disso, os autores também sugerem que o termo "conteúdos escolares" não se resume mais unicamente a uma listagem de conceitos científicos, mas que vai para além, por meio das temáticas.

A característica dos materiais produzidos e as perspectivas delineadas por Ibid (2017) reforçam o argumento de que, para haver real mudança no trabalho realizado em sala de aula, é fundamental que o material utilizado esteja coerente com as características do ensino que se 
deseja alcançar e que o licenciando tenha desde sua formação, contato com a prática de elaboração do material didático.

Para Silva \& Marcondes (2015) a autoria do material didático confere ao professor maior autonomia pedagógica, aumenta a criticidade com relação ao uso do livro didático e além de promover um aumento da autoestima.

Conforme Santos (2007) uma das principais queixas dos professores é a rigidez dos materiais didáticos disponíveis. A autora apresenta como alternativa, a elaboração de materiais didáticos mais flexíveis, e propõem o uso de unidades temáticas. Segundo a autora, além da elaboração de um material didático mais adequado, o professor também, principalmente no momento de sua formação, é estimulado a avaliar, analisar os materiais didáticos disponíveis, o que contribui para sua atuação futura, além de permitir uma maior proximidade com o mundo escolar real.

Contudo, pouco tem se encontrado na literatura brasileira sobre a utilização de unidades temáticas como estratégia para o ensino de ciências. No ensino de Química, podemos citar o trabalho realizado por Fonseca (2010), ao elaborar uma unidade temática sobre alimentos. No ensino de física tem destaque o trabalho de Rodrigues (2010). Além dos trabalhos de conclusão de curso como o realizado por Bischof (2018).

Segundo Borges \& Borges (1997) uma unidade temática (UT) deve propiciar ao professor de Química, uma variedade de estratégias e atividades para abordar o conhecimento científico, além de apresentar um conjunto de orientações que permitam a aplicação dessas atividades. Além disso, a UT deve apresentar um conjunto de orientações voltadas para o desenvolvimento das atividades por parte do aluno, como também reservar espaço para a realização das atividades. Também fazem parte de uma UT, segundo os autores, textos didáticos introdutórios, materiais e recursos alternativos, além de material avaliativo. O Guia do Professor deve conter as principais instruções para o andamento da aula.

O Guia do Aluno deve apresentar as orientações para os alunos acompanharem as atividades realizadas em sala de aula. O texto didático básico tem como característica principal, instruir sobre o conteúdo científico que está sendo abordado. Os materiais e recursos didáticos alternativos devem trazer sugestões de outras leituras, vídeos e/ou materiais que complementem ou aprofundem os conteúdos vistos em sala de aula.

As folhas de trabalho consistem em espaço reservado no material para anotações do aluno sobre experimentos, realização de exercícios ou demais anotações para si. Por fim, os materiais de avaliações da aprendizagem constituem exercícios e outras atividades que permitem ao professor acompanhar o desenvolvimento dos alunos. 
Research, Society and Development, v. 9, n. 8, e325985250, 2020

(CC BY 4.0) | ISSN 2525-3409 | DOI: http://dx.doi.org/10.33448/rsd-v9i8.5250

A Figura 1 ilustra a composição de uma unidade temática.

Figura 1 - principais aspectos que compõem uma unidade temática.

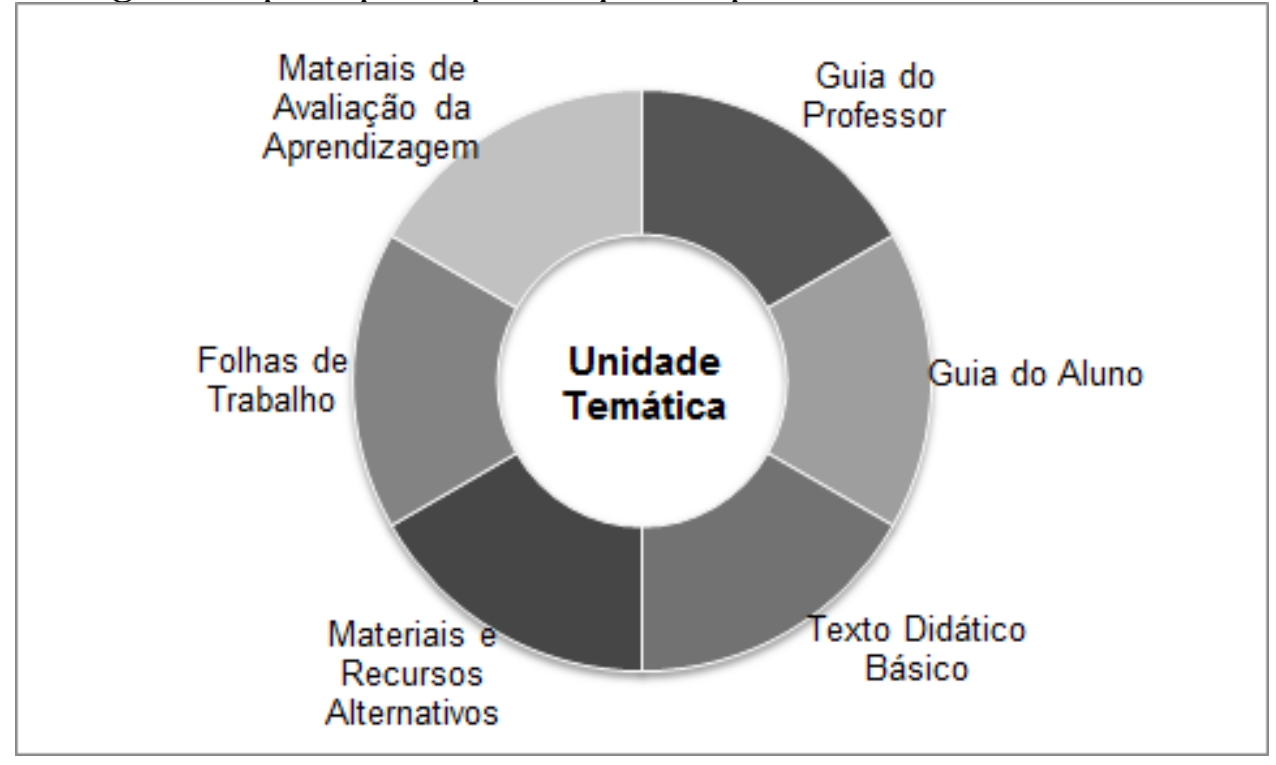

Fonte: Adaptado de Borges \& Borges (1997).

Na Figura 1, pode se observar que a Unidade Temática se trata de um material complexo, abrangente e ao mesmo tempo de natureza flexível. É importante destacar que a UT visa fornecer um conjunto de recursos que contribuam para as mais diversas formas de aprendizagem: vídeos, textos, atividades experimentais, exercícios, entre outras.

\subsection{A Temática da Higiene e Limpeza}

Conforme Silva e Gomes (2015), pode-se perceber que uma série de temáticas vêm sendo utilizadas ao longo dos últimos anos na elaboração de aulas e materiais didáticos diferenciados e que algumas, como meio ambiente e alimentação, são mais recorrentes que as demais. Porém, também é possível observar que a temática da higiene e limpeza não aparece dentre os temas, apesar de ser um aspecto comum do cotidiano dos alunos. $\mathrm{O}$ tema higiene e limpeza aparece, como tema gerador em Química, relacionado à limpeza de materiais ou vidrarias (Faria et al., 2016) ou vinculada a Química dos xampus, sabões e detergentes (Barbosa \& Silva, 1995; Verani, Gonçalves \& Nascimento, 2000). Muitas vezes a temática fica restrita aos conteúdos de Química orgânica, como nos estudos das reações orgânicas, a exemplo da reação de saponificação, e ao estudo dos grupos funcionais oxigenados. A temática da higiene e limpeza permite abordar conceitos químicos, como polaridade e 
solubilidade, até a discussão de questões ambientais, como a poluição por espuma em rios e lagos. Também, a partir da temática, é possível a discussão de temas de cunho social, como é o caso da leitura e interpretação da composição de rótulos de produtos de higiene pessoal e de limpeza. Dessa forma, a produção de uma unidade temática com este enfoque, como a apresentada neste estudo "A Química da Limpeza" acaba se tornando relevante. O ato de discutir questões que podem conscientizar sobre a postura em relação ao consumo de mercadorias é um dos objetivos do enfoque CTS. Normalmente os consumidores decidem o produto que comprarão somente pela aparência e função, e quase nunca, são considerados os aspectos sociais, ambientais e éticos envolvidos na sua produção e função.

\section{Metodologia de Pesquisa}

A pesquisa realizada neste trabalho tem como fundamentos teóricos a abordagem fenomenológica, uma vez que se dedica a estudar um fenômeno educacional, no caso, o desenvolvimento e a aplicação de uma unidade temática. Dentro desse contexto, optou-se pelo Estudo de Caso como metodologia para avaliar as potencialidades da unidade temática "A Química da Limpeza" no ensino de Química. Segundo Lüdke \& André (2013), o Estudo de Caso tem como características fundamentais a descoberta de novos elementos que podem surgir durante o estudo com base nos pressupostos teóricos escolhidos, a interpretação do contexto de estudo e o retrato da realidade presentes em uma determinada situação ou problema. Em um estudo de caso deve-se detalhar ou se aprofundar o máximo possível a descrição e entendimento do fenômeno como preconizam Pereira et al. (2018).

Também caracterizam o Estudo de Caso: o uso de uma variedade de fontes de informação, isto é, a coleta de dados se dá em diferentes momentos e situações, a possibilidade de generalizações, a representação de diferentes pontos de vista em uma situação social e a utilização de linguagem mais acessível (Ludke \& André, 2013). Nesse sentido, o Estudo de Caso compreende a coleta de dados em diversos momentos da pesquisa. Para isso foram coletados dados em três momentos: antes do início das atividades com as turmas, durante as aulas e ao final do período da pesquisa.

A pesquisa foi realizada durante 5 aulas de dois períodos, totalizando 10 horas-aula, com quatro turmas de primeiro ano do Ensino Médio, de uma escola pública estadual de Porto Alegre, no ano de 2017. No total, 33 alunos participaram no início e 44 no final da investigação. É pertinente salientar que a escola fica localizada em bairro com considerável 
vulnerabilidade social e que durante a coleta de dados os servidores estaduais encontravam-se em greve devido ao parcelamento dos salários.

Foram utilizados como instrumentos de coleta de dados os questionários adaptados de Rodrigues (2010). Foi aplicado um questionário inicial com o intuito de conhecer os alunos, bem como avaliar suas necessidades no ensino de Química e quais os seus interesses. Ao final do período da investigação foi aplicado um segundo questionário que tinha como objetivo avaliar a utilização da UT no ensino de Química com questões abertas e fechadas. Os questionamentos fechados empregados para a avaliação da UT foram elaborados utilizando uma escala do tipo Likert, a qual foi convertida a uma escala numérica, seguindo a descrição: 1 = DT (Discordo Totalmente); 2 = D (Discordo); 3 = NO (Não tenho opinião); 4 = C (Concordo); 5 = CT (Concordo Totalmente). A partir da escala numérica, foi possível calcular os escores para cada afirmativa, utilizando a equação 1 apresentada abaixo:

$$
R M=\frac{\sum(F i x V i)}{N T} \quad \text { Equação } 1
$$

Onde: $\mathrm{RM}=$ Ranking Médio (escores), $\mathrm{Fi}=$ Frequência Observada (por resposta $\mathrm{e}$ item), $\mathrm{Vi}=$ Valor de cada resposta, $\mathrm{NT}=$ Número Total de Respondentes. Os escores obtidos possuem valores variando entre 1 e 5 , onde os maiores valores indicam maior concordância com a respectiva afirmativa.

Por fim, também foi utilizado como instrumento de coleta de dados, o diário de campo das aulas. Onde foram registradas observações sobre o desenvolvimento das aulas. Os resultados foram analisados de forma interpretativa.

A UT elaborada para uma investigação em nível de Trabalho de Conclusão de Curso (Soares, 2018) foi planejada com atividades para cinco aulas, podendo ser utilizadas em conjunto, dado a sequência dos conteúdos, ou em separado, e sendo a primeira aula uma atividade de revisão do conteúdo de ligações Químicas. Também, a cada aula foi apresentada uma questão problematizadora, um texto introdutório e propostas algumas atividades, experimentais e/ou teóricas (atividades de pesquisa e leitura), além de referências e sugestões de leitura ou vídeo extras. O guia do professor encontra-se na introdução das cinco aulas.

\section{Resultados e Discussão}

Com o propósito de organizar a discussão dos dados que foram analisados de forma 
interpretativa, optou-se por apresentar inicialmente o perfil das turmas, na sequência como foi elaborada a UT, seguido dos apontamentos sobre as conquistas e desafios com sua implementação e por fim a avaliação das formas de contribuição da UT na pesquisa realizada.

\subsection{Caracterização das Turmas}

A idade dos alunos das turmas de primeiro ano mostrou-se variada entre 15 e 19 anos. Dos trinta e três respondentes das quatro turmas, vinte e dois tinham 15 ou 16 anos de idade, apenas seis alunos eram maiores de idade. Apesar de dois terços da turma estarem próximo da idade ou na idade adequada à seriação, foi possível observar que eram justamente alguns dos alunos mais velhos que estavam no controle das turmas, isto é, puxavam as brincadeiras, os momentos de conversa, enquanto outros mostravam-se bastante interessados e preocupados com as aulas.

Além das idades, também foi realizado um levantamento da importância dos conhecimentos de Química para os alunos. Sobre esse questionamento, pode-se perceber que os alunos se dividem, quase que igualmente, em três grupos: um que classifica os conhecimentos de Química como importantes (Sim, 11 respostas); um que não considera os conteúdos de Química importantes (Não, 12 respostas) e um terceiro grupo que não opina sobre (Sem resposta, 10), Figura 2.

Figura 2 - Gráfico das opiniões dos alunos quanto à importância dos conteúdos de Química.

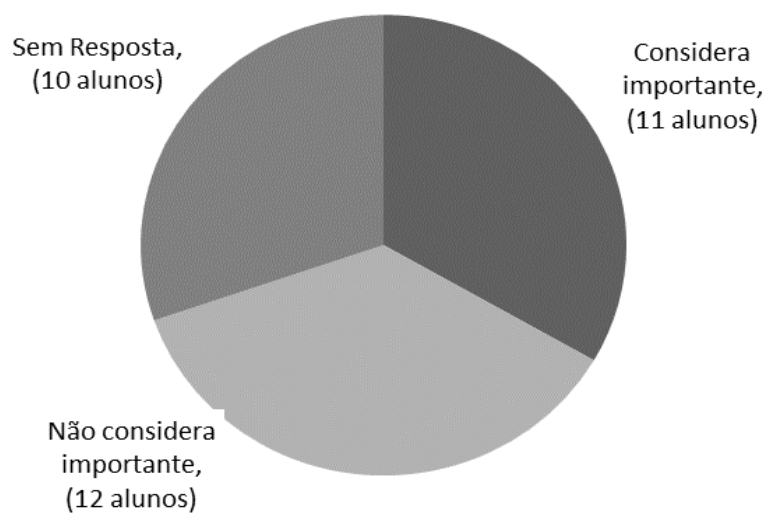

Fonte: Soares (2018).

Dos alunos que responderam sim, a grande maioria apenas respondeu "sim", mas não apresentou nenhuma justificativa à resposta. Porém, é possível destacar algumas justificativas, como: 
Aluno 9: "Sim, por que talvez no futuro eu possa usar no futuro para conseguir um emprego."

Aluno 16: "Sim, por que as vezes eu penso em ser cientista.

Da mesma forma, dos alunos que responderam "não", pode-se destacar as seguintes respostas:

Aluno 19: "Não. Por que eu não faço nada que use algo de Química."

Aluno 27: "Não muito por causa do tipo de trabalho que eu quero seguir."

Essas respostas demonstram que o ensino de Química desses alunos pode estar sendo trabalhado de forma descontextualizada e que não tem contemplado aspectos que relacionem a Química com o cotidiano dos alunos. Essa realidade é recorrente em relatos da literatura (Chassot, 1993; Silva \& Marcondes, 2010). Além disso, outro aspecto que fica evidente é o preconceito que os alunos possuem de que a Química somente é útil ao cientista (quem afinal trabalharia com Química se não o cientista?), como pode ser observado a partir das respostas dos alunos 16 e 27.

Também foi realizado um levantamento sobre as dificuldades dos alunos em Química. Entre os 33 respondentes, 19 disseram não ter nenhuma dificuldade com os conteúdos de Química, entretanto nove disseram ter dificuldades e apenas quatro não deram nenhuma resposta. Dos alunos que disseram ter dificuldades com os conteúdos de Química, pode-se perceber que estas se dão devido ao tipo de abordagem dos conceitos:

Aluno 7: "Sim, sobre os diferentes tipos de ligações moleculares e sua "classificação"”.

Aluno 30: "Sim. Em muitas fórmulas mais complexas."

Pela dificuldade apresentada pelo Aluno 7, de classificar os tipos de ligações Químicas, pode-se entender que os conceitos foram apresentados sem nenhuma contextualização ou referência que permitisse o aluno relacionar as ligações Químicas com outros conceitos, ou até mesmo com o seu cotidiano. O mesmo pode-se dizer sobre a resposta do Aluno 30, a apresentação de fórmulas desconectas de conceitos e fenômenos pode 
dificultar a compreensão dos conceitos. Outros ainda têm dificuldades que estão possivelmente relacionadas à desmotivação para estudar Química:

Aluno 22: "Sim, para mim nada faz sentido."

Desse modo, percebe-se a necessidade do desenvolvimento de estratégias de ensino que possam resgatar esses alunos desmotivados, visto que estes podem estar apresentando dificuldades de aprendizagem devido ao modelo tradicional de ensino. De modo geral, percebe-se um desinteresse dos alunos que participaram deste estudo com os conteúdos de Química. Isso pode estar relacionado ao fato, como bem apontado por Chassot (1993), de ainda prevalecer o ensino conteudista, sem contextualização e que não permite o desenvolvimento crítico do aluno.

\subsection{Elaboração da Unidade Temática}

De posse dos dados sobre o perfil dos alunos, deu-se início à elaboração da UT sobre limpeza. A elaboração da UT, do ponto de vista da preparação do material didático, possibilitou, como bem apontado por Santos (2007), um material bastante flexível, com variedade de atividades, desde experimentos, bem como de leituras e resolução de exercícios. Por se tratar de um material próprio, foi possível, além da flexibilização das aulas, a inserção de novas atividades ou questões problematizadoras ao longo do material, conforme o ritmo e qualidade do desenvolvimento das atividades e dos interesses dos alunos. Desse modo, fica evidente que a produção do próprio material didático contribui para a autonomia do professor em sala de aula, uma vez que não há dependência do livro didático (Del Pino et al., 1993). Além de ser um bom instrumento de atualização do conhecimento, a produção do material também permitiu a busca por materiais alternativos, como jogos e softwares que muitas vezes são deixados de lado.

Dentro da UT buscou-se diferentes estratégias para mitigar algumas necessidades dos alunos como: a carência de contextualização dos conceitos Químicos, as dificuldades de aprendizagem, ou ainda, a pequena motivação para participar das aulas. As aulas foram pensadas de modo que poderiam ser utilizadas em conjunto ou separadamente, conforme a disponibilidade.

Além de possibilitar a contextualização dos conteúdos a serem estudados, a temática da limpeza cumpre os requisitos de uma abordagem CTS ao permitir que sejam abordados 
conceitos nos três enfoques (Santos \& Mortimer, 2002). No âmbito da Ciência, o tema surfactantes pode ser abordado e problematizado pelo funcionamento químico dos sabões e detergentes. Do ponto de vista Tecnológico, os surfactantes aparecem presentes nos produtos cosméticos e de higiene pessoal, que por sua vez, estão ao alcance dos alunos em suas casas. Já a Sociedade pode ser abordada em diversos momentos, questionando a escrita e interpretação de rótulos de produtos de limpeza ou higiene, ou ainda, abordando a poluição das fontes de água doce, como os rios e lagos que recebem esgoto sem tratamento adequado.

Dessa forma, a cada aula buscou-se uma problematização dos conteúdos, de modo a instigar o pensamento reflexivo do aluno, o que é uma característica comum dos trabalhos envolvendo a abordagem CTS. Essa provocação servia para demonstrar que a Química estava de fato presente no dia a dia dos alunos, mesmo que estes não a percebessem, uma vez que, como apontado no questionário inicial, a grande maioria dos alunos não sabia reconhecer o papel da Química em seus cotidianos. Também se buscou mostrar que os conceitos estudados estavam interligados e que eles juntos eram necessários para a compreensão do funcionamento do detergente ao lavar a louça, por exemplo.

Sobre a temática escolhida, limpeza, também é preciso levantar algumas reflexões. Primeiramente, a Química dos surfactantes envolve o estudo do funcionamento dos sabões e detergentes e que geralmente é abordada somente no terceiro ano do Ensino Médio, no ensino de funções e reações orgânicas. A desconstrução da ideia dos produtos de limpeza relacionados apenas aos conteúdos de Química Orgânica mostrou-se bastante desafiadora, uma vez que os alunos do primeiro ano ainda não possuem o conhecimento das funções orgânicas, e pouco material didático envolvendo o tema fora do contexto da orgânica está disponível. Dessa forma, para a maioria das aulas e atividades propostas, fez-se a construção completa do material desde a elaboração dos textos e exercícios, bem como escolha das figuras e exemplos ilustrativos.

Em segundo lugar, a temática da limpeza permite a abordagem de tópicos que algumas vezes acabam sendo negligenciados durante as aulas de Química como segurança e leitura e interpretação dos rótulos, os quais são temas sociais relevantes. Segundo o Sistema Nacional de Informações Tóxico-Farmacológicas, em 2016, cerca de 13\% dos acidentes de intoxicação, envolveram produtos cosméticos e dominissanitários (Sinitox, 2016). Dessa forma, a abordagem com os alunos da importância da leitura dos rótulos, bem como a apresentação de cuidados com o manuseio e armazenamento foi feita na UT, em uma atividade com embalagens de produtos de higiene e beleza. 
Por fim, a temática envolvendo produtos de higiene e cosméticos possibilitou o debate de questões ambientais importantes, como a poluição de rios e das fontes de captação de água. Essa abordagem foi feita na UT por meio da apresentação de vídeo, e de um debate sobre a composição de detergentes utilizados para lavar louça. Além disso, durante a aula de polaridade buscou-se apresentar as consequências da imiscibilidade do óleo e água quando ocorrem os derramamentos ou vazamentos de petróleo na natureza.

\subsection{Aplicação da UT: conquistas e desafios}

Como mencionado anteriormente, o período no qual foi realizada a pesquisa foi marcado pelas greves dos professores da rede pública estadual devido ao parcelamento dos salários. Dessa forma, o primeiro desafio encontrado na aplicação da UT foi a falta de frequência dos alunos na disciplina de Química.

Conforme relatos no Diário de Campo, um desafio encontrado já na primeira aula, foi a compreensão da linguagem utilizada para a discussão sobre a revisão de Ligações Químicas. Palavras como, "constituído" e "macroscópico" geraram dúvidas nos alunos, que não conheciam seus significados.

Apesar desses percalços, uma das vantagens da utilização de UTs é a possibilidade de utilizar cada aula independentemente das demais. Então, a cada dois períodos, em geral, começava-se um tópico novo, que permitia que mesmo os alunos com muitas faltas, em algum momento, participassem das discussões sobre a temática da limpeza e a partir disso novos conceitos de Química eram trabalhados.

As problematizações acerca da temática apareceram em diferentes momentos na UT. Em algumas aulas os exemplos e exercícios utilizados abordavam a questão de produtos de limpeza, a fim de contextualizar os conceitos que seriam abordados. Já em outras aulas, foi justamente a limpeza que gerou a problematização que permitiu a abordagem dos conceitos Químicos. Essas problematizações tinham como intuito fomentar o debate em sala, porém, como os alunos não estão habituados a metodologias diferenciadas, foi bastante difícil fazer com que os alunos participassem da discussão. Essa passividade na realização dos debates pode ser atribuída ao modelo de ensino vivenciado em grande parte das aulas de Química, nas quais os estudantes estão habituados a reproduzir o conhecimento apresentado pelo professor (Chassot, 2001). Para vencer essa passividade foi preciso dialogar muito com os alunos e mostrar que eles também são cidadãos e que podem e devem questionar aspectos do cotidiano. 
Ao final do período da pesquisa, os alunos estavam mais propensos a participar das discussões feitas em sala de aula. Como exemplo, tem-se a aula em que foi realizada a Atividade Experimental: Leite Psicodélico (Manual do Mundo, 2020). Após a realização do experimento os alunos eram convidados a responder algumas questões para fomentar a discussão e teorização sobre polaridade e solubilidade. De forma geral o resultado foi muito positivo. Os alunos debateram e discutiram entre si para ver quem tinha a hipótese mais acertada sobre o que estavam observando. Praticamente, todos os alunos das turmas apontaram hipóteses ou fizeram perguntas para saber mais sobre o assunto. Até mesmo durante a teorização, os alunos apresentaram sugestões e dúvidas e participaram ativamente.

Aqui fica claro o argumento de Halmenschlager \& Delizoicov (2017) que, para haver real mudança no trabalho realizado em sala de aula, é fundamental que o material utilizado esteja coerente com as características do ensino que se deseja alcançar. Com a atividade realizada foi possível instigar o interesse dos alunos, para buscar a explicação do fenômeno a partir da teoria que foi apresentada durante a discussão.

Outra proposta da UT era a utilização de modelos físicos (Francisco Júnior, Ferreira \& Hartwig, 2009) para o ensino da geometria molecular. Foram construídos dois modelos, um de balões, outro de canudos de refrigerante e bolhas de sabão e ainda utilizado um modelo padrão de bolas e palitos. Os modelos eram manuseados pelos alunos a fim de facilitar a compreensão espacial do posicionamento dos átomos. A grande vantagem da utilização dos modelos se deu pelo fato dos alunos não conhecerem as formas geométricas, principalmente as tridimensionais como o tetraedro, pirâmide e octaedro.

Além de auxiliar na explicação sobre a geometria tetraédrica, o modelo de canudos também serviu para abordar novamente a temática limpeza, uma vez que para que o tetraedro pudesse ser visualizado, era necessário mergulhar o modelo na água com sabão. Desse modo, as bolhas de sabão unidas formavam exatamente os eixos do tetraedro e bem no centro do modelo era possível visualizar a posição do átomo central. A utilização do modelo estimulou a participação dos alunos com perguntas, principalmente sobre as bolhas de sabão, além de ter chamado bastante a atenção por ser um modelo não usual. Conforme apontam Francisco Júnior, Ferreira e Hartwig (2009) o uso de modelos físicos favorece o desenvolvimento de habilidades, o entendimento em nível microscópico mediante a representação visual e facilita a compreensão dos conceitos, por possibilitar o contato direto e a manipulação de objetos.

Conforme apontado na literatura, a abordagem CTS visa promover a educação científica e tecnológica dos alunos, de forma a desenvolver habilidades, construir saberes e adquirir os valores necessários para atuarem como cidadãos responsáveis em áreas 
relacionadas à ciência e o emprego de suas tecnologias na sociedade (Santos \& Mortimer, 2002).

Por fim, também foi proposto na UT a apresentação de um vídeo sobre a temática da limpeza. Nesse vídeo foi possível abordar aspectos como o surgimento dos detergentes durante a Segunda Guerra Mundial, as interações intermoleculares e a poluição de rios pelo excesso de espuma produzida pelos detergentes. Durante a apresentação do vídeo, em vários momentos, foram feitas pausas para conversar com os alunos sobre o que estava sendo mostrado. Dentre as pausas feitas, a discussão sobre a poluição mostrou ser muito produtiva, uma vez que vários estudantes disseram que já haviam visto a espuma em arroios perto de suas casas.

\subsection{Avaliação da UT}

Ao final do período da investigação, foi aplicado um novo questionário com o intuito de avaliar as atividades propostas do ponto de vista dos alunos, e da utilização da UT como estratégia de ensino de Química. Para isso, foram elaboradas perguntas fechadas sobre a autoavaliação dos estudantes e uma avaliação descritiva da UT.

Uma pergunta fechada com cinco afirmativas seguindo uma escala do tipo Likert foi utilizada para identificar o grau de concordância dos sujeitos a respeito da utilização da UT. Desse modo, quanto maior o escore obtido, maior o número de alunos concordantes com a afirmativa.

Conforme pode ser observado na Figura 3, as afirmativas 2 e 5 apresentaram escores acima de 4,0, o que sugere que a maioria dos alunos concorda que a utilização da UT de fato contribuiu para a contextualização dos conceitos de Química abordados (afirmativa 2). Além disso, a utilização de atividades experimentais foi o item que mais contribuiu para motivar a aprendizagem dos alunos (afirmativa 5). Esse resultado possivelmente está relacionado à boa participação em aula dos alunos nos dias em que foi realizada a atividade experimental do Leite Psicodélico. 
Research, Society and Development, v. 9, n. 8, e325985250, 2020

(CC BY 4.0) | ISSN 2525-3409 | DOI: http://dx.doi.org/10.33448/rsd-v9i8.5250

Figura 3 - Opiniões dos estudantes quanto às contribuições da UT.

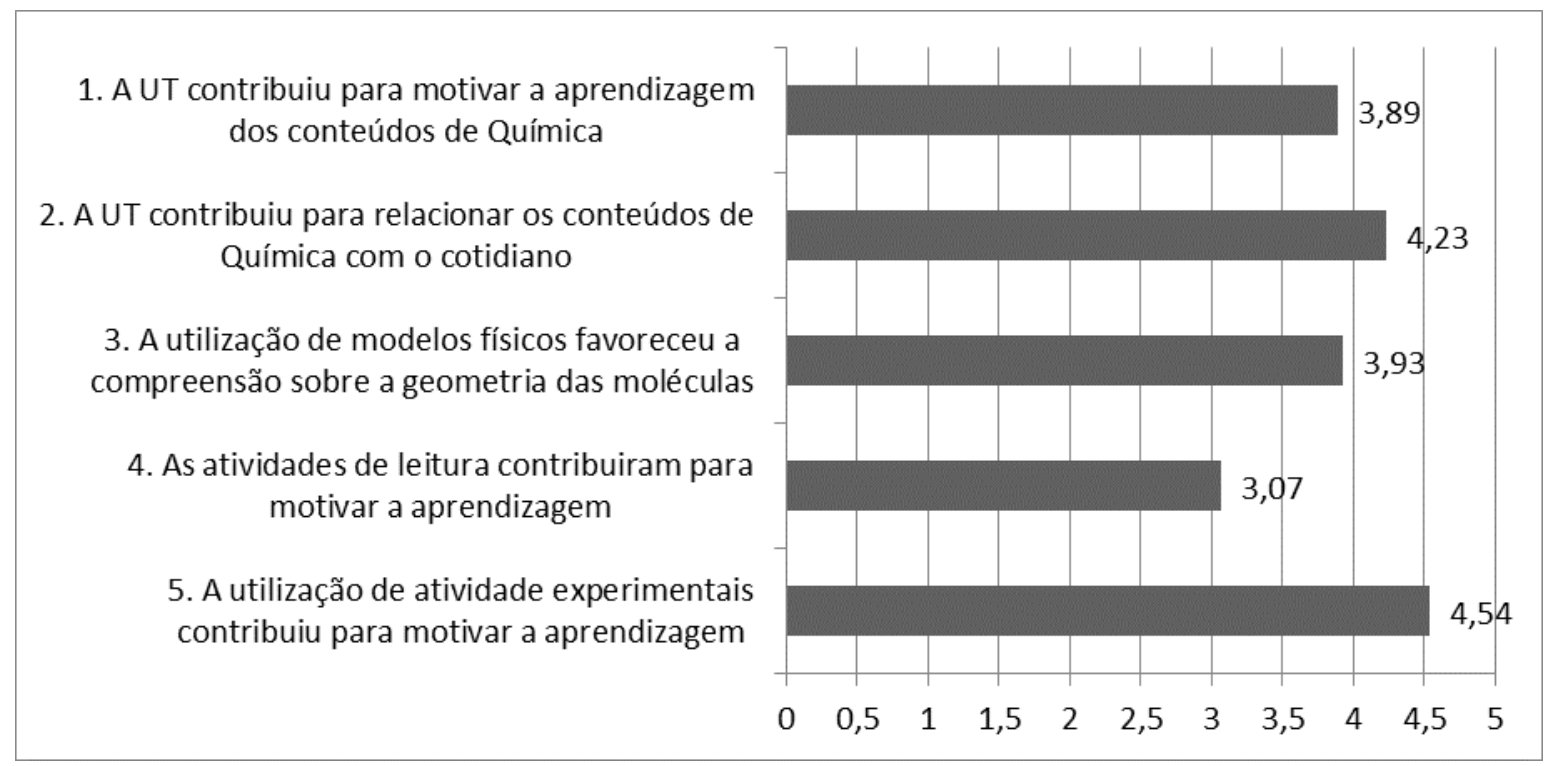

Fonte: Soares (2018).

O alto escore na questão 5 pode ser confirmado pelas respostas dadas pelos alunos na questão aberta sobre a avaliação da UT (Você acredita que atividades diferenciadas, como aulas práticas, leituras e uso de modelos físicos como as apresentadas no material didático utilizado durante as aulas podem contribuir para o aprendizado dos conteúdos de química? Justifique.):

Aluno 1: "Sim, com certeza ajuda para a aprendizagem do aluno. Não fica naquela coisa monótona de escrever no caderno e o professor falando."

Aluno 25: "Sim, acredito que aprendemos mais quando colocamos em prática o conteúdo passado."

Por outro lado, a utilização de atividades de leitura, foi a que menos motivou os alunos, como pode ser observado na Figura 3, pelo escore mais baixo obtido para a afirmativa $4(3,07)$. As atividades de leitura são mais triviais em sala de aula, e desse modo, podem não ter contribuído da mesma forma para despertar o interesse dos alunos, como as atividades práticas. Além disso, possivelmente as dificuldades com a linguagem utilizada acabaram levando os alunos a discordarem da utilização de atividades de leitura como algo motivador, como fica claro no depoimento do aluno 8:

Aluno 8: "Sim, aulas práticas ajudam a compreender melhor a matéria, porém a linguagem utilizada tornou um pouco complicado o entendimento." 
Research, Society and Development, v. 9, n. 8, e325985250, 2020

(CC BY 4.0) | ISSN 2525-3409 | DOI: http://dx.doi.org/10.33448/rsd-v9i8.5250

Esse mesmo aluno marcou que discordava com o uso de atividades de leituras como forma de motivar o ensino de Química.

As afirmativas 1 e 3, buscavam identificar a concordância dos alunos com o fato da UT auxiliar para motivar a aprendizagem, e com a utilização de modelos físicos para favorecer a compreensão da geometria das moléculas, respectivamente. Apesar de não apresentarem escores superiores a 4, pode-se observar que estes escores ficaram muito próximos ao valor referente ao Concordo. Desse modo, a fim de analisar se essas respostas indicavam uma contribuição positiva, foi preciso observar os dados obtidos nas demais questões abertas.

$\mathrm{Na}$ questão aberta fez-se um levantamento das opiniões dos estudantes sobre a utilização do material didático. Os resultados encontram-se no Quadro 1, seguinte.

Quadro 1 - Opinião dos alunos quanto à utilização do material didático.

\begin{tabular}{|l|c|}
\hline \multicolumn{1}{|c|}{ Alternativa } & Número de alunos \\
\hline As atividades propostas exigiram muito raciocínio & 11 \\
\hline As atividades foram compreendidas sem grandes dificuldades & 20 \\
\hline A linguagem utilizada foi de difícil compreensão & 2 \\
\hline As problematizações feitas pela professora me motivaram a realizar as atividades & 7 \\
\hline Prefiro quando a professora passa matéria no quadro & 3 \\
\hline
\end{tabular}

Fonte: Soares (2018).

Conforme observado no Quadro 1, parte dos alunos (11 de 43) acredita que as atividades propostas exigiram muito raciocínio e que preferiam quando a professora passava matéria no quadro (3 de 43). As dificuldades encontradas durante as aulas, para fazer com que os alunos debatessem questões sociais, como o fato dos rótulos de produtos de higiene e beleza estarem em inglês, ou por que na composição dos detergentes são adicionados conservantes, podem ser exemplos da passividade dos alunos. Durante as aulas, buscaram-se diversas investidas para que o debate ocorresse, no entanto, as respostas dos alunos eram evasivas ou apenas concordando com o que estava sendo dito pela professora. Somente nas últimas aulas foi possível identificar a elaboração de comentários mais críticos acerca da temática limpeza, como análise de rótulos, consumo excessivo de produtos industrializados e cuidados com o descarte das embalagens. 
Como apontam Silva \& Mortimer (2002), os estudantes apresentam resistência ao modelo de aula dialógica, na qual eles podem e devem opinar, apresentar seus pontos de vista. Pois normalmente as aulas de ciências são marcadas pela presença de conhecimentos absolutos e verdadeiros que são apresentados pelos professores e que devem apenas serem reproduzidos por eles.

No ensino tradicional os alunos não precisam empregar muito esforço nas atividades, uma vez que se trata de mera repetição do que o professor coloca no quadro. Quando os alunos são convidados a sair da zona de conforto do ensino tradicional (Leão, 1999), normalmente encontra-se resistência, pois se passa a exigir um raciocínio mais crítico e não apenas repetitivo. Conforme registros no Diário de Campo, além das observações feitas em aula como a citada acima, quando os alunos deveriam realizar uma atividade de pesquisa em casa, eram comuns frases do tipo: "Ah, eu odeio pesquisar!" ou "lá vem a sora com essas pesquisas”.

Essas respostas encontram-se alinhadas com os escores mais baixos obtidos nas afirmativas 1 e 4 . Nessas questões, pode-se relacionar o baixo escore com o grande número de alunos que disseram que as atividades propostas exigiam muito raciocínio. Além disso, somente sete alunos disseram que as problematizações feitas em sala de aula motivaram para realizar as atividades. Isso mostra um reflexo da dificuldade encontrada durante a proposição dos debates. Nesse sentido, Silva \& Marcondes (2015) apontam que cabe ao professor incitar as discussões, para que o paradigma do ensino tradicional seja superado.

Em contrapartida, 20 alunos disseram que as atividades propostas na UT foram compreendidas sem grandes dificuldades. Isso mostra que mesmo que parte dos alunos ainda resista às mudanças na forma de ensino, a maioria já as aceita, e compreendem quais os objetivos dessas novas estratégias, como exemplificado pelas respostas dadas pelos alunos 29 e 11:

Aluno 29: "Acho que quanto mais diferenciadas forem as aulas, mais interesse desperta no aluno."

Aluno 11: "Sim. Uma aprendizagem diferente desperta interesse nos alunos."

Também foi realizada uma autoavaliação pelos alunos. Nessa autoavaliação, era permitido que o aluno marcasse mais de uma alternativa. Os resultados podem ser observados no Quadro 2. 
Quadro 2 - Autoavaliação dos alunos.

\begin{tabular}{|l|c|}
\hline \multicolumn{1}{|c|}{ Alternativa } & $\begin{array}{c}\text { Número de } \\
\text { alunos }\end{array}$ \\
\hline As aulas motivaram-me para a resolução de atividades & 19 \\
\hline Não me senti motivado com as atividades propostas na UT & 4 \\
\hline Não realizei as atividades da UT de forma responsável & 2 \\
\hline Tenho a impressão que a cada aula aprendi novos conceitos & 28 \\
\hline Acredito que a professora deveria continuar trabalhando dessa maneira diferente & 21 \\
\hline Não aprendi coisas novas durante as aulas & 0 \\
\hline Os assuntos abordados em aula não despertavam o meu interesse & 4 \\
\hline
\end{tabular}

Fonte: Soares (2018).

Como pode ser observado no Quadro 2, 21 alunos disseram que a professora deve continuar a trabalhar de maneira diferenciada e 28 alunos disseram ter aprendido coisas novas a cada aula. Nenhum aluno disse não ter aprendido nada novo. Além disso, esses resultados indicam que o escore obtido para a afirmativa 1, de 3,89, na Figura 3, aponta para uma concordância entre os alunos sobre as contribuições motivacionais da UT para a realização das atividades

Esses dados também colaboram com os dados obtidos nas afirmativas 1 e 2 (Figura 3), uma vez que ratificam o uso da UT como relevante e que de fato contribuiu para motivar a aprendizagem dos conceitos de Química abordados.

Conforme registros no Diário de Campo, a maior parte dos estudantes apresentou resultado satisfatório nas atividades avaliativas que compunham a UT, assim como nas provas aplicadas pela professora titular da turma.

Os resultados apontados no trabalho de Rodrigues (2010) com a UT sobre energia, assemelham-se muito aos obtidos neste trabalho e nos desafios encontrados. Essa convergência nos resultados contribui para mostrar que há um enfrentamento constante de desafios ao propor novas atividades nas aulas de Química, pois o ensino tradicional ainda continua muito enraizado nas escolas. Desse modo, pode-se inferir que a produção de um material didático diferenciado, como uma UT, em que se use a contextualização a partir da perspectiva CTS, é uma estratégia válida no ensino de ciências. 


\section{Considerações Finais}

A utilização da UT “A Química da limpeza” permitiu utilizar atividades diversificadas em sala de aula e observar como os alunos reagiam frente a essas propostas. A maior dificuldade encontrada no período da investigação foi retirar os alunos da zona de conforto (Leão, 1999) do sistema de ensino tradicional, pois como comentado ao longo do trabalho, os alunos com frequência reclamavam das atividades de pesquisa e resistiam para participar dos debates propostos.

Outro benefício da escolha de uma UT como estratégia para o ensino de geometria molecular, polaridade e solubilidade e interações intermoleculares, foi a necessidade de um aprofundamento teórico por parte da professora em formação, para a elaboração do material didático. A utilização da temática da limpeza a diferentes atividades constituiu um desafio, mas que ao ser levado para a sala de aula mostrou compensar o esforço, pois em diversos momentos, mesmo depois de muita argumentação, foi possível expandir a discussão para outros temas relacionados. Essa expansão acrescentou tanto aos alunos, como para a formação da professora pesquisadora, uma vez que se pode perceber que muitos momentos importantes da aula são construídos por perguntas inusitadas e que surgiram apenas pelo fato de os alunos terem sua curiosidade estimulada, principalmente na atividade prática Leite Psicodélico.

Por fim, destaca-se que a utilização de UTs construídas com um enfoque CTS pode contribuir para a formação de um aluno capaz de compreender a sociedade que vive de forma crítica, isto é, contribuir para a formação de um cidadão capaz de atuar de forma consciente na sociedade (Giffoni, Barroso \& Sampaio, 2020; Santos \& Mortimer, 2002; Strieder \& Kawamura, 2017).

Contudo, enquanto a escola e os alunos permanecerem desassistidos pelas políticas públicas, pouca mudança ocorrerá na sala de aula no sentido de implementação de práticas inovadoras. Mesmo diante de um sistema de iniquidades e de interesses fortemente voltados para as classes mais abastadas, ainda se busca a oxigenação do ensino público por meio da inserção e formação de novos professores. Deve-se estimular a produção de material didático adaptado à realidade dos alunos, além da inserção de temas cotidianos em sala de aula, como foi o caso da UT "A química da limpeza" apresentada nesse trabalho. Aos professores, sugere-se que busquem atualizações constantes, mesmo de aulas já consideradas prontas, como no caso a expansão da temática limpeza para higiene pessoal e saúde. As unidades temáticas constituem uma ferramenta importante não só na disciplina de química, mas 
também em atividades multidisciplinares. A universidade pública cumpre um papel importante na formação de professores nesse sentido, e deve buscar manter-se na vanguarda do ensino, mesmo diante de tantos desafios.

\section{Referências}

Auler, D. (2002). Interações entre Ciência-Tecnologia-Sociedade no Contexto da Formação de Professores de Ciências. 257p. Tese (Doutorado em Educação). UFSC, Florianópolis, SC, Brasil.

Auler, D., Dalmolin, A. M. T., \& Fenalti, V. S. (2009). Abordagem temática: natureza dos temas em Freire e no enfoque CTS. Alexandria Revista de Educação em Ciência e Tecnologia, 2(1), 67-84.

Barbosa, A. B., \& Silva, R. R. (1995). Xampus. Química Nova na Escola, 2, 3-6.

Bischoff, E. (2018). Desenvolvimento de uma metodologia para análise de unidades temáticas. Trabalho de Conclusão de Curso (Curso de Licenciatura em Química) - UFRGS, Porto Alegre, RS, Brasil.

Borges, O. N., \& Borges, A. T. (1997). Reformulação do Currículo de Física do Ensino Médio no Estado de Minas Gerais. I Encontro Nacional de Pesquisa em Ensino de Ciências. Porto Alegre, 432-441.

Brasil. (1996). Lei n. 9394 de 20 de dezembro de 1996. Lei de Diretrizes e Bases da Educação Nacional. Recuperado em: 07 abril, 2020.

Chassot, Á. I. (1993). Catalisando Transformações na Educação. Ijuí: UNIJUI.

Chassot, Á. I. (2001). Alfabetização Científica: questões e desafios para a educação. Ijuí: UNIJUI. 
Cruz, S. M. S. (2001). Aprendizagem Centrada em Eventos: uma experiência com enfoque em Ciência, Tecnologia e Sociedade no Ensino Fundamental. 258p. Tese (Doutorado em Educação). UFSC, Florianópolis, SC, Brasil.

Dagnino, R. \& Thomas, H. (2003). Ciência, Tecnologia e Sociedade: uma Reflexão Latinoamericana. Taubaté: Cabral Editora e Livraria Universitária.

Del Pino, J. C., Chassot, Á. I., Schroeder, E. O., Salgado, T. D. M., \& Krüger, V. (1993). Química do Cotidiano: Pressupostos Teóricos para a Elaboração de Material Didático Alternativo. Espaços da Escola, 3(10), 47-53.

Delizoicov, D. (2008). La Educación en Ciencias y la Perspectiva de Paulo Freire. Alexandria Revista de Educação em Ciências e Tecnologia, 1(2), 37-62.

Faria, D. L. A., Bernardino, N., Setubal, S. R. M., Novais, V., \& Constantito, V. R. L. (2016). Limpando Moedas de Cobre: Um Laboratório Químico na Cozinha de Casa. Química Nova na Escola, 38(1), 20-24.

Fonseca, C. V. (2010). Química, Nutrição e Ensino Médio: produção de material didático no enfoque das representações sociais. 295p. Dissertação (Mestrado em Química), UFRGS, Porto Alegre, RS, Brasil.

Francisco Júnior, W. E., Ferreira, L, H, \& Hartwig, D. R. (2009). Um modelo para o estudo do fenômeno de deposição metálica e conceitos afins. Química Nova na Escola, 31(2), 82-87.

Giffoni, J. S., Barroso, M. C. S., \& Sampaio, C. G. (2020). Significant learning in Chemistry teaching: a science, technology and society approach. Research, Society and Development, 9(6), 13963416.

Halmenschlager, K. R., \& Delizoicov, D. (2017). Abordagem Temática no Ensino de Ciências: Caracterização de Propostas Destinadas ao Ensino Médio. Alexandria Revista de Educação em Ciência e Tecnologia, 10(2), 305-330. 
Leão, D. M. M. (1999). Paradigmas contemporâneos de educação: escola tradicional e escola construtivista. Cadernos de Pesquisa, (107), 187-206.

Ludke, M., \& André, M. (2013). Pesquisa em Educação: abordagens qualitativas. Rio de Janeiro: E. P. U.

Lutfi, M. (1992). Os Ferrados e Cromados: produção social e apropriação privada do conhecimento químico. Ijuí: UNIJUÍ.

Manual do Mundo. Leite Psicodélico com corante e detergente. (2020). Disponível em: https://www.youtube.com/watch?v=8dY3jRUPGXI. Recuperado em: 07 abril, 2020.

Pereira, A. S., Shitsuka, D. M., Parreira, F. J.; Shitsuka, R. (2018). Metodologia da pesquisa científica. [e-book]. Santa Maria. Ed. UAB/NTE/UFSM. Disponível em: https://repositorio.ufsm.br/bitstream/handle/1/15824/Lic_Computacao_MetodologiaPesquisa-Cientifica.pdf?sequence=1. Recuperado em: 23 junho, 2020.

Rodrigues, M. F. (2010). A Temática da Energia Proposta Através de Temas Geradores para a Sexta-série do Ensino Fundamental. 122p. Dissertação (Mestrado em física), UFRGS, Porto Alegre, RS, Brasil.

Roehrig, S. A. G., Assis, K. K., \& Czelusniaki, S. M. (2011). A Abordagem CTS no Ensino de Ciências: Reflexões sobre as Diretrizes Curriculares Estaduais do Paraná. IV Simpósio Nacional de Tecnologia e Sociedade. Curitiba, 1-10.

Santos, F. M. T. (2007). Unidades Temáticas - Produção de Material Didático Por Professores em Formação Inicial. Experiências em Ensino de Ciências, 2(1), 1-11.

Santos, W. L. P. (1992). Ensino de Química para Formar o Cidadão: Principais características e condições para a sua implantação na escola secundária brasileira. 233p. Dissertação (Mestrado em Educação), Universidade Estadual de Campinas, Campinas, SP, Brasil. 
Santos, W. L. P., \& Mortimer, E. F. (2002). Uma Análise de Pressupostos Teóricos da Abordagem C-T-S (Ciência - Tecnologia - Sociedade) no Contexto da Educação Brasileira. Ensaio - Pesquisa em Educação em Ciências, 2(2), 1-13.

Silva, E. L., \& Marcondes, M, E, R. (2015). Materiais didáticos elaborados por professores de Química na perspectiva CTS: uma análise das unidades produzidas e das reflexões dos autores. Ciência e Educação, 21(1), 65-83.

Silva, E. L., \& Marcondes, M, E, R. (2010). Visões de Contextualização de Professores de Química na Elaboração de Seus Próprios Materiais Didáticos. Revista Ensaio, 12(01), 101118.

Silva, R. R., \& Gomes, V. B. A. (2015). Seção Química e Sociedade: Contribuições para um Ensino em Diferentes Contextos. Química Nova na Escola, 37(2), 146-153.

Sinitox - Sistema Nacional de Informações Tóxico-Farmacológicas. (2016). Casos Registrados de Intoxicação Humana e Envenenamento. (2016). Disponível em: https://sinitox.icict.fiocruz.br/dados-nacionais. Recuperado em 07 abril, 2020.

Soares, F. A. (2018). A elaboração e uso de uma unidade temática sobre limpeza no ensino de química. 88 p. Trabalho de Conclusão de Curso (Licenciatura em química). UFRGS, Porto Alegre, RS, Brasil.

Strieder, R. B., \& Kawamura, M. R. D. (2017). Educação CTS: Parâmetros e Propósitos Brasileiros. Alexandria Revista de Educação em Ciência e Tecnologia, 10(1), 27-56.

Toma, R. B., Greca, I. M., \& Meneses-Villagrá, J. Á. (2017). Dificultades de maestros en formación inicial para diseñar unidades didácticas usando la metodología de indagación. Revista Eureka sobre enseñanza y divulgación de las ciencias, 14(2), 441-457.

Verani, C. N., Gonçalves, D, R., \& Nascimento, M. G. (2000). Sabões e Detergentes Como Tema Organizador de Aprendizagens no Ensino Médio. Química Nova na Escola, 12, 15-19. 
Research, Society and Development, v. 9, n. 8, e325985250, 2020

(CC BY 4.0) | ISSN 2525-3409 | DOI: http://dx.doi.org/10.33448/rsd-v9i8.5250

Porcentagem de contribuição de cada autor no manuscrito

Franciela Arenhart Soares - 50\%

Ágatha Lottermann Selbach - 20\%

Camila Greff Passos - 30\% 